\title{
Solution-processed amorphous gallium-tin oxide thin film for low-voltage, high-performance transistors
}

\author{
Jinhua Ren, Kaiwen Li, Jianwen Yang, Dong Lin, Haoqing Kang, Jingjing Shao, Ruofan Fu and \\ Qun Zhang*
}

\begin{abstract}
Gallium-tin oxide (GTO) semiconductor thin films were prepared by spin-coating with 2-methoxyethanol as the solvent. Their crystal structures, optical transparency, chemical states and surface morphologies, along with the electrical properties, were dependent on $\mathrm{Ga}$ contents and annealing temperatures. The optimized GTO channel layer was applied in the high- $k \mathrm{Al}_{2} \mathrm{O}_{3}$ thin film transistor (TFT) with a low operation voltage of $2 \mathrm{~V}$, a maximum field-effect mobility of $69 \mathrm{~cm}^{2} \mathrm{~V}^{-1} \mathrm{~s}^{-1}$, a subthreshold swing (SS) of $76 \mathrm{mV} \mathrm{dec}{ }^{-1}$, a threshold voltage of $0.67 \mathrm{~V}$ and an on-off current ratio of $1.8 \times 10^{7}$. The solution-processed amorphousGTO-TFTs would promote the development of low-consumption, low-cost and high performance In-free TFT devices.
\end{abstract}

Keywords: GTO semiconductor films, thin-film transistor, stability, $\mathrm{Al}_{2} \mathrm{O}_{3}$ dielectric

\section{INTRODUCTION}

Amorphous oxide semiconductors (AOS) are achieving attention over amorphous silicon and low-temperature polycrystalline silicon (LTPS) recently [1]. $\mathrm{In}_{2} \mathrm{O}_{3}, \mathrm{ZnO}$ and $\mathrm{SnO}_{2}$ based semiconductors are promising candidates for information displays [2-4]. Particularly, mass production of amorphous-InGaZnO (a-IGZO) panel has been realized. However, In is a rare element $(0.25 \mathrm{ppm})$ in the earth's upper continental crust, prompting researchers to exploit In-free materials [5]. As for Zn-Sn-O (ZTO) [6] and $\mathrm{ZnON}$ [7], weak $\mathrm{Zn}-\mathrm{O}$ bonds in their lattice lead to instable thin film transistor (TFT) devices [8]. Hence, $\mathrm{SnO}_{2}$ based semiconductors are emerging as promising channel materials. In the $\mathrm{SnO}_{2}$-based channels, $\mathrm{Sn}^{4+}$ with a $4 \mathrm{~d}^{10} 5 \mathrm{~s}^{0}$ electronic configuration can contribute to the high mobility, which is similar to the 5 s orbital of $\mathrm{In}^{3+}$ (IGZO) [9]. $\mathrm{In}^{3+}$ may be replaced by $\mathrm{Sn}^{4+}$ in TFTs to avoid high fabrication cost. In the last few years, Yang et al. [10-12] prepared high performance $\mathrm{SnO}_{2}$-based TFTs by radio-frequency $(\mathrm{RF})$ magnetron sputtering. It is well known that ion bombardment and incorporation results in a large number of defects in the films [13]. In addition, in the sputtering process, multi-metal thin film probably has different composition from the target due to preferential sputtering, especially for IGZO [14]. Therefore, more researchers are turning to solution process method for realizing low-cost electronics. Recent reports $[15,16]$ showed solution processed $\mathrm{SnO}_{2}$ TFTs have better performance than vacuum based devices. Pure $\mathrm{SnO}_{2}$ films tend to crystallize, which does not lead to the uniformity for TFT devices. Besides, high carrier concentration in pure $\mathrm{SnO}_{2}$ also affects the electrical performance of devices, such as stability and current on-off ratio $\left(I_{\text {on }} / I_{\text {off }}\right)$. From the periodic table of elements, it can be found that the similar ion radius of $\mathrm{Ga}(0.62 \AA)$ and $\mathrm{Sn}(0.69 \AA)$ may reduce structural defects in the Ga-doped $\mathrm{SnO}_{2}$ system. In the previous reports $[17,18], \mathrm{Ga}$ is an oxygen vacancy inhibitor and can weaken the crystallinity of films. Recently, Matsuda et al. [19] reported RF magnetron sputtered a-GaSnO (GTO)-TFTs with high mobility of $25.6 \mathrm{~cm}^{2} \mathrm{~V}^{-1} \mathrm{~s}^{-1}$ at $350^{\circ} \mathrm{C}$. Zhang et al. [20] reported nanocrystalline Ga-rich GTO-TFTs with mobility of $1.03 \mathrm{~cm}^{2} \mathrm{~V}^{-1} \mathrm{~s}^{-1}$ at $900^{\circ} \mathrm{C}$. The high annealing temperature is not compatible with high- $k$ dielectric and flexible substrates.

In this paper, solution-processed a-GTO-TFTs with various $\mathrm{Ga}$ content and under different annealing temperatures are investigated. The stability of the optimum device is evaluated. Based on these results, a-GTO-TFTs with $\mathrm{Al}_{2} \mathrm{O}_{3}$ high- $k$ dielectric layer show high mobility and low operation voltage.

Department of Materials Science, National Engineering Laboratory for TFT-LCD Materials and Technologies, Fudan University, Shanghai 200433, China

*Corresponding author (email: zhangqun@fudan.edu.cn) 


\section{EXPERIMENTAL SECTION}

\section{Precursor solution preparation}

$0.1 \mathrm{~mol} \mathrm{~L}^{-1} \mathrm{SnCl}_{2} \cdot 2 \mathrm{H}_{2} \mathrm{O}$ (Aladdin, 99.99\%) and various amounts of $\mathrm{Ga}\left(\mathrm{NO}_{3}\right)_{3} \cdot x \mathrm{H}_{2} \mathrm{O}$ (Aladdin, 99.9\%) (Ga: $\mathrm{Sn}=0$, $10,20,50$ at.\%) were dissolved in $10 \mathrm{~mL} \mathrm{2-methox-}$ yethanol successively in sealed reagent bottles. Then, they were stirred by a magnetic stirrer at room temperature for $2 \mathrm{~h}$ in ambient. For $\mathrm{Al}_{2} \mathrm{O}_{3}$ dielectric, $0.3 \mathrm{~mol} \mathrm{~L}^{-1}$ $\mathrm{Al}\left(\mathrm{NO}_{3}\right)_{3} \cdot 9 \mathrm{H}_{2} \mathrm{O}$ (Aladdin, 99.99\%) was dissolved in $5 \mathrm{~mL}$ 2-methoxyethanol and then stirred at room temperature for $3 \mathrm{~h}$.

\section{Thin film and device fabrication}

For GTO-SiO $\mathrm{S}_{2}$ device, p-Si with $270 \mathrm{~nm}$ thermally grown $\mathrm{SiO}_{2}$ was cleaned by acetone, ethyl alcohol and deionized water successively. Then the surface of $\mathrm{SiO}_{2}$ was treated by oxygen plasma to improve the adhesive strength of GTO solution. The above GTO solutions were filtered through $0.22 \mu \mathrm{m}$ PTFE filter and then spin-coated onto the $\mathrm{SiO}_{2}$ substrate with the rotation speed of $3,500 \mathrm{rpm}$ for $30 \mathrm{~s}$. The sol films were then baked on a hot plate to be preheated at $150^{\circ} \mathrm{C}$ for $10 \mathrm{~min}$ to evaporate the solvent. The resulting gel films were annealed in a tube furnace at 300,350 and $400^{\circ} \mathrm{C}$ for $1 \mathrm{~h}$ in air. Finally, ITO source/ drain (S/D) electrode arrays $(W / L=450 \mu \mathrm{m} / 80 \mu \mathrm{m}, W$ and $L$ is width and length of electrodes) were deposited by RF magnetron sputtering. For GTO- $\mathrm{Al}_{2} \mathrm{O}_{3}$ device, $\mathrm{p}$-Si wafers were ultrasonically cleaned by $2 \% \mathrm{HF}$ aqueous solution, water, acetone and ethyl alcohol. Similarly, they were bombarded with oxygen plasma to improve hydrophilicity. The prepared $\mathrm{Al}^{3+}$ solution was also filtered through $0.22 \mu \mathrm{m}$ PTFE filter and spun onto the Si wafers. Then, it was pre-annealed on a hotplate at $220^{\circ} \mathrm{C}$ for $10 \mathrm{~min}$. The samples were then cured under ultraviolet lamp for $10 \mathrm{~min}$ to promote the crosslinking reactions in the gel film. Taking the annealing temperature of active layers into account, the cured $\mathrm{Al}_{2} \mathrm{O}_{3}$ gel films were then annealed at $450^{\circ} \mathrm{C}$ in air for $30 \mathrm{~min}$. The fabrication method of channel layers is similar to the GTO-SiO device. The entire device was completed after the deposition of ITO electrodes. In the meantime, the GTO films were also spin-coated on a glass substrate under the same condition.

\section{Thin film and device characterization}

The thermal behavior of GTO and $\mathrm{Al}_{2} \mathrm{O}_{3}$ precursor solutions was monitored in ambient air using a thermal gravimetric (TGA, TA Q500) with a heating rate of $10^{\circ} \mathrm{C} \mathrm{m^{-1 }}$. The film thicknesses were measured via a stylus profiler (Kosaka Laboratory ET3000). The device structure was observed by a field-emission scanning electron microscope (FE-SEM-4800-1) in sectional view. The surface information of thin films was detected by energy disperse spectroscopy (EDS) attachment. X-ray diffraction (XRD, Bruker D8 Advanced and Da Vinci Design system) was used to characterize the crystal structure of thin films. Optical transmittance of GTO films was obtained from ultraviolet-visible (UV, Shimad$\mathrm{zu}$, UV2400) spectrophotometer. X-ray photoelectron spectroscopy (XPS, ThermoFischer, ESCALAB 250Xi) was used to analyze the chemical components and oxidation states of the surfaces of GTO channels. The surface morphologies of active layer were examined by an atomic force microscope (AFM, Dimension Edge, Bruker). The capacitance per unit area of $\mathrm{Al}_{2} \mathrm{O}_{3}$ dielectric layer was measured with a WK6515B precision impedance analyzer. $I-V$, transfer and output characteristic curves of GTO-TFTs were measured by a Keithley 4200 semiconductor parameter analyzer.

\section{RESULTS AND DISCUSSION}

Fig. 1a shows the TGA curves of $\mathrm{Al}_{2} \mathrm{O}_{3}$ and 20 at.\% GTO gels where the initial weight loss below $130^{\circ} \mathrm{C}$ is due to the evaporation of 2-methoxyethanol (gray region). The gradual weight loss up to $400^{\circ} \mathrm{C}$ for $\mathrm{Al}_{2} \mathrm{O}_{3}$ gel is ascribed to the evaporation of the bound water and the decomposition of nitrate groups (yellow region) [21]. For GTO gel, condensation process gradually leads to a network of $\mathrm{Ga}-\mathrm{Sn}-\mathrm{O}$ bonds with increasing temperature (yellow region) [20]. The faster mass loss for $\mathrm{Al}_{2} \mathrm{O}_{3}$ gel may originate from the lower $\mathrm{Al}^{3+}$ weight ratio in the $\mathrm{Al}_{2} \mathrm{O}_{3}$ precursor solution (7.2 wt.\%) than that of GTO solution (52.6 wt.\% for $\mathrm{Sn}^{4+}, 27.3 \mathrm{wt} . \%$ for $\mathrm{Ga}^{3+}$ ). Fig. $1 \mathrm{~b}$ shows the XRD patterns of GTO thin films on glass substrates annealed at $350^{\circ} \mathrm{C}$ with Ga content from 0 to 50 at.\%. The pure $\mathrm{SnO}_{2}$ film shows a weak peak at $2 \theta=37.9^{\circ}$, representing (200) crystal planes of cassiterite $\mathrm{SnO}_{2}$ (JCPDS No. 41-1445) [22]. The poor crystallinity may be due to a low temperature. It is reported that $\mathrm{SnO}_{2}$ films present obvious polycrystalline peaks at the temperature above $350^{\circ} \mathrm{C}$ [16]. However, the unobvious peak after doping 10 at.\% Ga indicates that Ga can inhibit the crystallization of $\mathrm{SnO}_{2}$ lattice. As the $\mathrm{Ga}$ content increases to 20 and 50 at.\%, GTO thin film becomes amorphous. The degradation of $\mathrm{SnO}_{2}$ thin film crystallinity may derive from the induced stress and the distortion of structures [18]. Due to ionic radius difference, $\mathrm{Ga}^{3+}$ may occupy $\mathrm{Sn}^{4+}$ sites in GTO films. Optical spectra of GTO films demonstrate the transmit- 

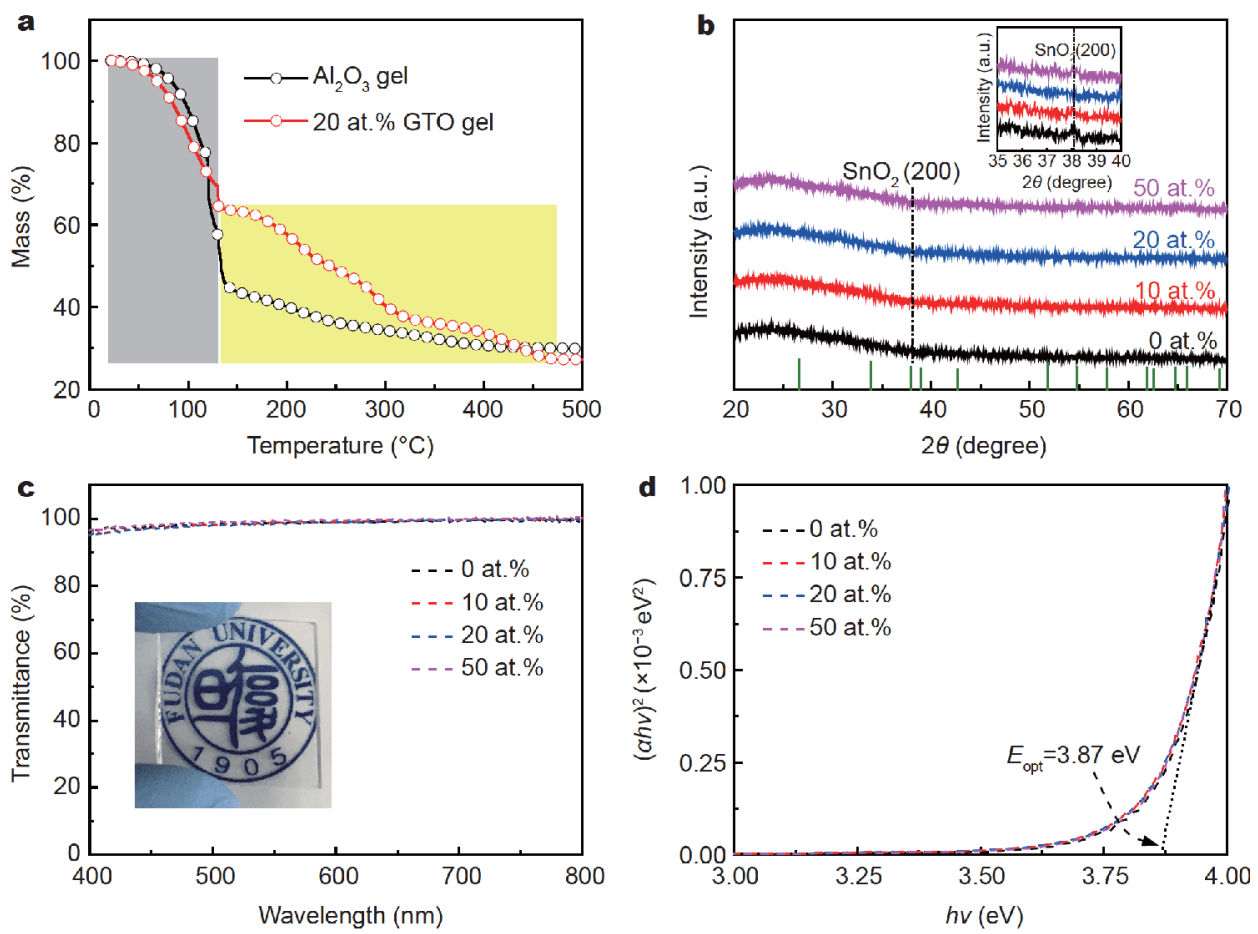

Figure 1 (a) TGA curves of $\mathrm{Al}_{2} \mathrm{O}_{3}$ and 20 at.\% GTO gels, (b) XRD patterns of GTO thin films, (c) optical transmittance of a-GTO thin films (inset: the photograph of 20 at.\% GTO thin film), (d) Tauc plots of a-GTO thin films.

tance more than $95 \%$ from 400 to $700 \mathrm{~nm}$ (Fig. 1c). The optical bandgap $\left(E_{\mathrm{g}}\right)$ of GTO films, calculated from the formula: $(\alpha h v)^{2}=A\left(h v-E_{\mathrm{g}}\right)$, where $\alpha$ is absorption coefficient, is around $3.87 \mathrm{eV}$. This value is larger than that of IGZO films $(3.17-3.38 \mathrm{eV})$, indicating their excellent optical performance [23]. We do not observe the obvious red shift of bandgap after $\mathrm{Ga}$ incorporation which is consistent with a previous report [17].

The concentration of oxygen defects plays an important role in determining the carrier concentration of oxide semiconductor thin films, and thus affects the electrical performance of TFTs including mobility $(\mu)$ and threshold voltage $\left(V_{\text {th }}\right)$. Hence, XPS measurements were conducted to reveal the chemical information of GTO channels, as depicted in Fig. 2. The binding energies (BE) of all elements were calibrated with reference to the $\mathrm{C} 1 \mathrm{~s}$ line at $284.6 \mathrm{eV}$ for charge shift effect. In Fig. 2a, O 1s peaks were deconvoluted into three sub-peaks at $530.4 \mathrm{eV}$ (M-O-M lattice oxygen, $\mathrm{O}_{\mathrm{I}}$ ), $531.3 \mathrm{eV}$ (oxygen defects, $\mathrm{O}_{\text {II }}$ ) and $532.3 \mathrm{eV}$ (adsorbed oxygen: $\mathrm{O}_{2}, \mathrm{OH}$ species, $\mathrm{O}_{\text {III }}$ ) respectively $[24,25]$. It has been calculated that the atomic ratios of $\mathrm{O}_{\text {II }}$ component $\left(\mathrm{O}_{\text {II }} /\left(\mathrm{O}_{\mathrm{I}}+\mathrm{O}_{\text {II }}+\mathrm{O}_{\text {III }}\right)\right)$ are $24.5 \%$, $33.7 \%, 41.6 \%, 36 \%$ and $15.1 \%$ for the samples annealed at $300^{\circ} \mathrm{C}, 350^{\circ} \mathrm{C}, 400^{\circ} \mathrm{C}(20$ at. $\% \mathrm{Ga})$ and the samples doped with 0,50 at. $\% \mathrm{Ga}\left(350^{\circ} \mathrm{C}\right.$ annealing temperature).
Oxygen defects related to carrier concentration can be modulated by altering annealing temperatures and doping contents. The $\mathrm{O}_{\text {III }}$ component decreases from $22.5 \%$ to $10.9 \%$ when the temperature increases from 300 to $400^{\circ} \mathrm{C}$. $\mathrm{OH}$-related species become heavily oxidized at high temperature in accordance with the TGA results. $\mathrm{O}_{\mathrm{I}}$ component slightly decreases (53\% to $47.5 \%$ ) as the temperature increases, leading to the loss of metal atoms during the high temperature treatment [26]. It is well known that the adequate amount of carriers in the channel layer is beneficial to the off-operation mode of normal TFTs. Nevertheless, excess carriers will make channels difficult to be depleted [27]. Consequently, the excess electrons in the conductive $\mathrm{SnO}_{2}$ thin film must be inhibited to achieve the enhancement-mode TFT device. The Sn 3d peaks at $486.4\left(\mathrm{Sn} 3 \mathrm{~d}_{5 / 2}\right)$ and $494.8 \mathrm{eV}(\mathrm{Sn}$ $3 \mathrm{~d}_{3 / 2}$ ) [20] do not obviously shift after Ga incorporation, indicating the oxidation state of Sn element is not affected evidently, as shown in Fig. 2b. The shift of $\sim 0.3 \mathrm{eV}$ to higher BE of Sn 3d shows more metal bonds in 50 at.\% GTO film as evidenced in $\mathrm{O}$ 1s peak. The BE range for $\mathrm{Sn}^{4+}$ ions is $486-487.1 \mathrm{eV}$ [28]. From Fig. 2c, Ga 3d peaks are located at $20.2 \mathrm{eV}$ [20]. The Ga and Sn orbital peaks in the full spectra (Fig. S1) indicate the successful fabrication of GTO thin films lays the foundation for 

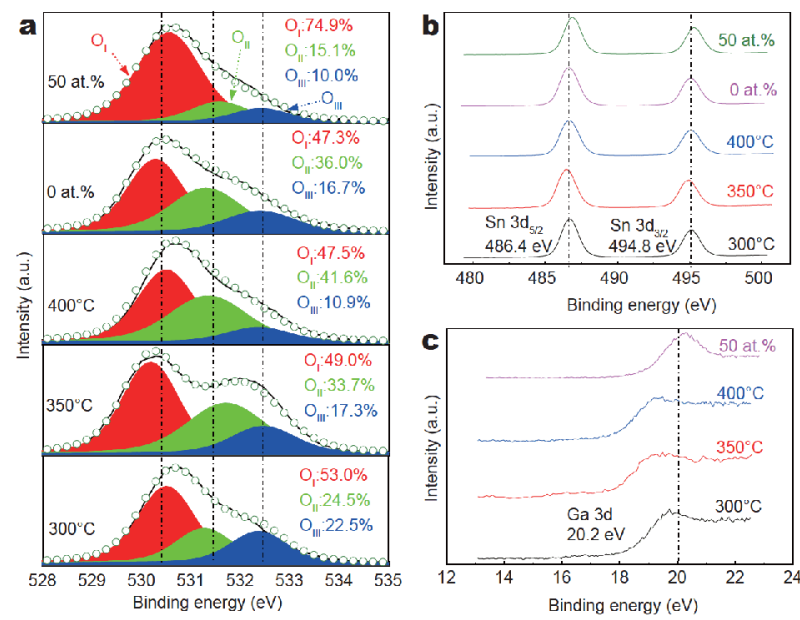

Figure 2 (a) O 1s XPS fine spectra of GTO channels under different annealing temperatures $\left(300,350\right.$ and $400^{\circ} \mathrm{C}$ at 20 at.\% Ga) and doping contents ( 0 and 50 at. $\% \mathrm{Ga}$ at $350^{\circ} \mathrm{C}$ ), (b) XPS spectra of Sn $3 \mathrm{~d}$ region, (c) XPS spectra of Ga $3 \mathrm{~d}$ region.
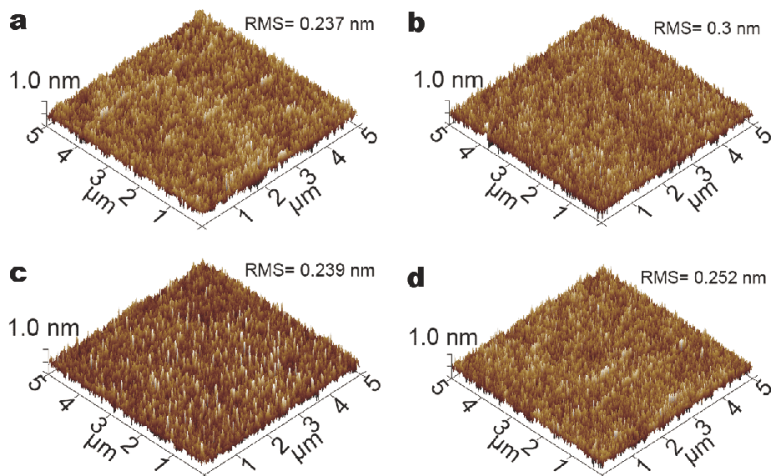

Figure 3 AFM morphologies of GTO channels with Ga content at (a) 0 , (b) 10 , (c) 20, (d) 50 at.\%.

the subsequent fabrication of TFT devices.

AFM images of GTO channels are shown in Fig. 3. No evident grain accumulation on GTO channels may be responsible for the weak crystallization or amorphous state. The root-mean-square (RMS) roughness of 0.237 , $0.300,0.239$ and $0.252 \mathrm{~nm}$ for the samples with $0,10,20$ and 50 at.\% Ga, respectively, indicates that $\mathrm{Ga}$ doping exerts no obvious effects on the surface undulation. It is well known that low RMS roughness reduces carrier scattering and ensures the high performance of TFTs [29]. This may be due to the small radius difference between $\mathrm{Ga}^{3+}$ and $\mathrm{Sn}^{4+}$.

Based on above results, bottom-gate top-contact TFTs were fabricated with GTO thin films. The top view of channels is shown in Fig. 4a. Fig. 4b shows the FE-SEM cross sectional image of the 20 at.\% GTO-TFT. The thicknesses of GTO layer and ITO electrode are about 35 and $50 \mathrm{~nm}$, respectively. The corresponding EDS pattern of the thin film indicates the uniformity of elements distribution (Fig. S2). $I-V$ curves were carried out to test the electrical contact properties of GTO-TFTs with different Ga contents (Fig. 4c, inset: test schematic). Linear dependence in positive and negative bias voltage ranges demonstrates the low-resistance contact between ITO electrodes and GTO thin films, which indicates ohmic contacts [30]. The typical transfer curves of samples with different annealing temperatures and $\mathrm{Ga}$ doping contents are shown in Fig. $4 \mathrm{~d}$ and $4 \mathrm{e}$. The detailed device parameters calculated from transfer characteristic curves are shown in Table 1. The field effect mobility $\left(\mu_{\mathrm{FE}}\right)$ is calculated from $\mu_{\mathrm{FE}}=\left(\mathrm{d} I_{\mathrm{D}} / \mathrm{d} V_{\mathrm{G}}\right) /\left(C_{\mathrm{i}} W V_{\mathrm{D}} / L\right)$ at low $V_{\mathrm{D}}$ [31] (Fig. S3). From Fig. $4 \mathrm{~d}$, it can be seen that GTO devices with superior performance can be formed at $350^{\circ} \mathrm{C}$. Nevertheless, low annealing temperature will lead to poor mobility and large SS. It is reported that the degree of oxygen defects generation is dependent on the annealing temperature which affects the electron concentration in channels, which has been elucidated by XPS results [32]. It is reported that electron transport in AOS semiconductors is predominant by hopping percolation mechanism and accelerated with increasing electron concentration $[33,34]$. Although the GTO3-TFT (Table 1) has higher mobility than those annealed at lower temperature, its SS deteriorates and $V_{\text {th }}$ shifts to the more negative values, leading to high energy consumption. From Fig. 4e, as $\mathrm{Ga}$ doping content increases from 0 to 20 at.\%, the off-state current decreases from $3 \times 10^{-5}$ to $4 \times 10^{-11} \mathrm{~A}$, which demonstrates that Ga element acts as the carrier inhibitor in the GTO system. It is also known that a larger metal ion electronegativity $\left(\chi_{z}\right)$ difference will control the oxygen defects more effectively [35]. The electronegativity difference of $\mathrm{Ga}(3+)$ (1.756) and $\mathrm{O}$ (3.61) is slightly more than that of $\mathrm{Sn}(4+)(1.824)$ and $\mathrm{O}$, leading to carrier suppression effect [36]. It is worth noting that Shin et al. [37] also observed the charge carrier suppression effect in GTO-TFTs fabricated via cosputtering method. Nevertheless, oxygen chemical states are unknown in channel layers. When $\mathrm{Ga}$ content increases to 50 at.\%, the mobility degrades seriously as $I_{\text {on }}$ decreases and $V_{\text {th }}$ also shifts more positively. From above results, the appropriate doping level in our experimental conditions is 20 at.\%. The $\mu_{\mathrm{FE}}, \mathrm{SS}, V_{\mathrm{th}}$ and $I_{\text {on }} / I_{\text {off }}$ are $6.8 \mathrm{~cm}^{2} \mathrm{~V}^{-1} \mathrm{~s}^{-1}, 0.9 \mathrm{~V} \mathrm{dec}^{-1}, 0.7 \mathrm{~V}$ and $2.1 \times 10^{6}$, respectively, in enhancement mode, demonstrating the reliability of these solution-processed GTO channels in the fabrication of TFTs on $\mathrm{SiO}_{2}$ substrates. Fig. $4 \mathrm{f}$ shows 
a

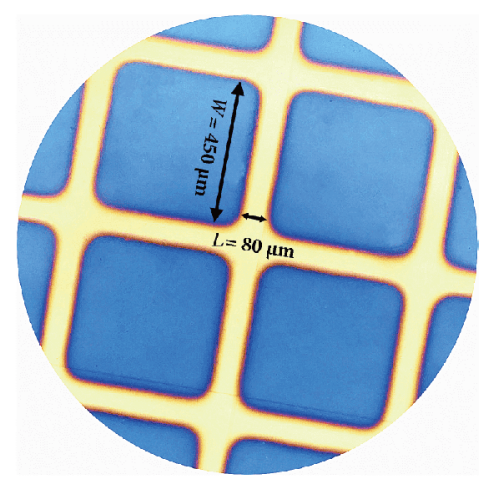

b

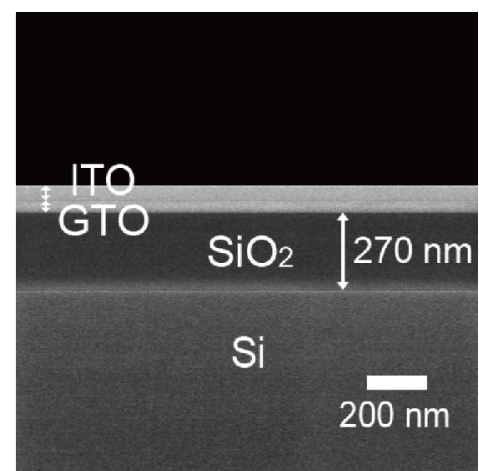

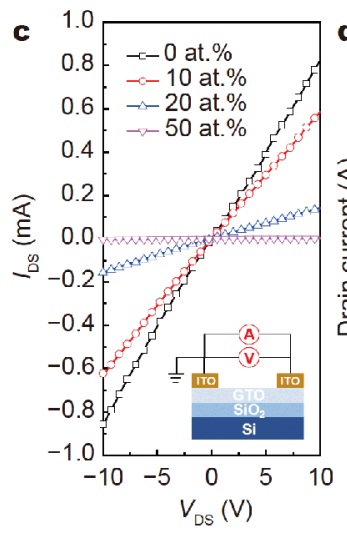
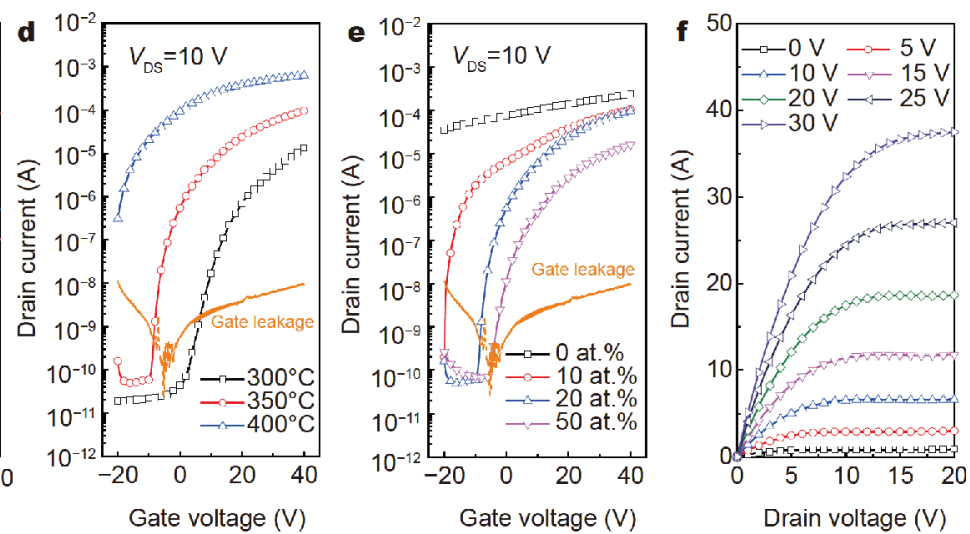

Figure 4 (a) The top view of GTO-TFT channels, (b) FE-SEM cross sectional view of the 20 at.\% GTO-TFT, (c) $I-V$ curves of GTO channels with different Ga contents, (d) transfer curves of GTO-TFTs under different annealing temperatures, (e) transfer curves of GTO-TFTs with different Ga doping contents, (f) output curves for the GTO-TFT with Ga content of 20 at.\%. All of TFTs are swept with the gate voltage from -20 to $40 \mathrm{~V}$ at $V_{\mathrm{DS}}=10 \mathrm{~V}$.

Table 1 Fundamental parameters and performance of GTO- $\mathrm{SiO}_{2}$ and $\mathrm{GTO}-\mathrm{Al}_{2} \mathrm{O}_{3}$ devices

\begin{tabular}{ccccccc}
\hline Sample & Doping content (at.\%) & Temperature $\left({ }^{\circ} \mathrm{C}\right)$ & $\mu_{\mathrm{FE}}\left(\mathrm{cm}^{2} \mathrm{~V}^{-1} \mathrm{~s}^{-1}\right)$ & $\mathrm{SS}\left(\mathrm{V} \mathrm{dec}^{-1}\right)$ & $V_{\text {th }}(\mathrm{V})$ & $I_{\text {on/off }}$ \\
\hline GTO1 & 20 & 300 & $1.2-1.7$ & $2.1-2.3$ & $7.0-8.7$ & $5.0 \times 10^{4}-4.6 \times 10^{5}$ \\
GTO2 & 20 & 350 & $6.8 \pm 0.4$ & $0.9 \pm 0.4$ & $0.7 \pm 0.6$ & $(1.0-2.1) \times 10^{6}$ \\
GTO3 & 20 & 400 & $8.7-9.6$ & $1.6-1.9$ & $<-20$ & $\sim 10^{2}-2.0 \times 10^{3}$ \\
GTO4 & 0 & 350 & 11.8 & 28.7 & $<-20$ & $\sim 10^{1}$ \\
GTO5 & 10 & 350 & $9.2-9.9$ & $0.3-1.0$ & $-13--9.2$ & $5.0 \times 10^{4}-5.2 \times 10^{5}$ \\
GTO6 & 20 & 350 & $6.8 \pm 0.4$ & $0.9 \pm 0.4$ & $0.7 \pm 0.6$ & $(1.0-2.1) \times 10^{6}$ \\
GTO7 & 50 & 350 & $0.9-1.5$ & $1.3-2.0$ & $5.8-7.0$ & $2.5 \times 10^{5}-1.7 \times 10^{6}$ \\
GTO- $\mathrm{Al}_{2} \mathrm{O}_{3}$ & 20 & 350 & 69 & 0.076 & 0.67 & $1.8 \times 107$ \\
\hline
\end{tabular}

the typical output characteristic curves of the optimized TFT (GTO6, see Table 1) which exhibits the hard saturation at $V_{\mathrm{D}}=20 \mathrm{~V}$.

To our knowledge, there are almost no reports about the stability of solution processed $\mathrm{SnO}_{2}$ based TFTs. The stabilities of TFTs are crucial to the application of display backplanes such as AMLCDs and AMOLEDs. Fig. 5a shows clockwise hysteresis characteristic of GTO6-TFT at
$V_{\mathrm{DS}}=1$ and $10 \mathrm{~V}$. The hysteresis voltage shift is about $9.2 \mathrm{~V}$ at $V_{\mathrm{DS}}=100 \mathrm{nA}$. Positive bias stress (PBS) and negative bias stress (NBS) tests were carried out at bias voltages of $+20 \mathrm{~V}$ and $-20 \mathrm{~V}$ for $1,200 \mathrm{~s}$ (Fig. $5 \mathrm{~b}$ and $5 \mathrm{c}$ ). In the PBS test, the $V_{\text {th }}$ positively shifts by $\sim 6.6 \mathrm{~V}$ which is larger than that of sputtered GTO-TFTs under the same stress time [19]. We can observe a slightly decreased SS with the extension of time because more interface states 

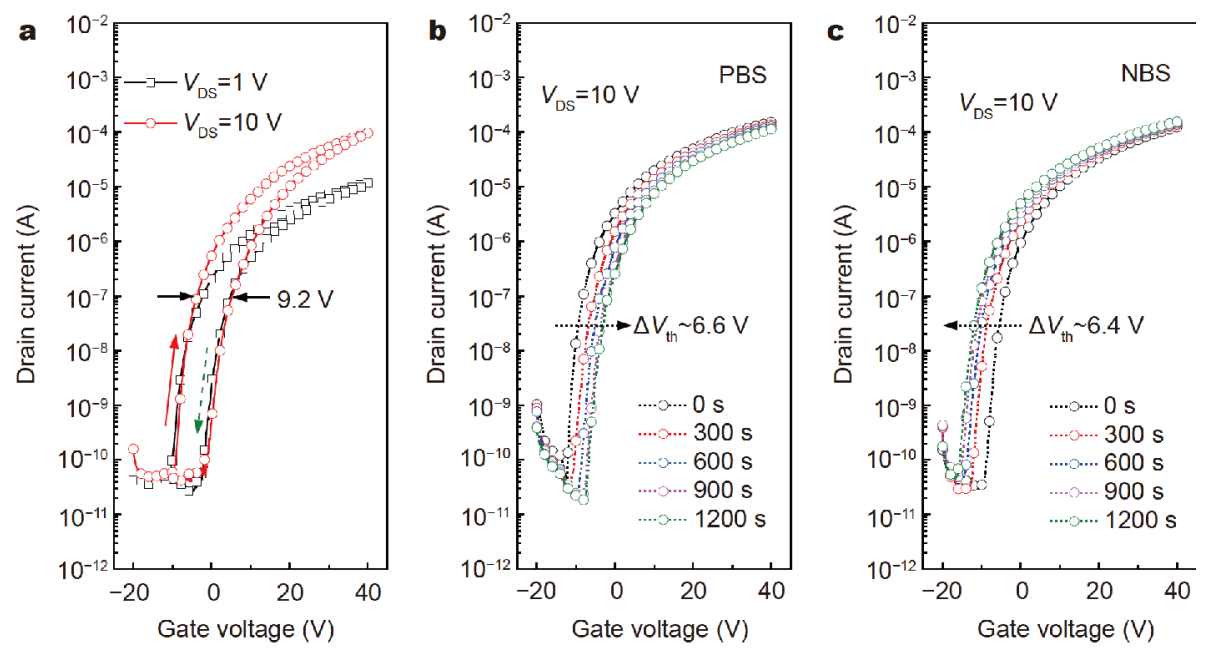

Figure 5 (a) Hysteresis characteristic of 20 at.\% GTO-SiO ${ }_{2}$-TFT, (b) PBS test, (c) NBS test.

are filled during PBS process [38]. On the other hand, it is reported that the electric field applied in the channel layer can result in the adsorption of $\mathrm{O}_{2}$ (acceptor) and desorption of adsorbed $\mathrm{H}_{2} \mathrm{O}$ (donor) which can reduce electrons in the channel layer [39]. Both mechanisms can contribute to the positive $V_{\text {th }}$ shift. Besides, the $V_{\text {th }}$ negatively shifts by $\sim 6.4 \mathrm{~V}$ under NBS after the device is stressed $1,200 \mathrm{~s}$, which can be explained by the $\mathrm{H}_{2} \mathrm{O}$ adsorption mechanism [40]. In this case, the mechanism can be expressed by $\mathrm{H}_{2} \mathrm{O}+\mathrm{h}^{+}=\mathrm{H}_{2} \mathrm{O}^{+}$where $\mathrm{h}^{+}$and $\mathrm{H}_{2} \mathrm{O}^{+}$ are holes in the channel layer and water molecules positively charged on the back surface of channel layer. Although GTO-TFTs have been fabricated by solution process on $\mathrm{SiO}_{2}$ substrates successfully, they are confronted with many challenges such as low mobility, high SS and instability, making them insufficient to be put into practice.

In order to improve the a-GTO-TFT performance, $\mathrm{SiO}_{2}$ was replaced by $\mathrm{Al}_{2} \mathrm{O}_{3}$ thin film as the dielectric layer. XRD pattern of $\mathrm{Al}_{2} \mathrm{O}_{3}$ thin film exhibits its amorphous state (Fig. 6a). The RMS roughness of $0.16 \mathrm{~nm}$ in the area of $5 \times 5 \mu \mathrm{m}^{2}$ can be derived from the AFM image of $\mathrm{Al}_{2} \mathrm{O}_{3}$ thin film. The leakage property of $\mathrm{Al}_{2} \mathrm{O}_{3}$ thin film with the thickness of $\sim 30 \mathrm{~nm}$ is shown in Fig. 6b. It can be obtained that the breakdown field strength of $\sim 4.4 \mathrm{MV} \mathrm{cm}^{-1}$ ensures the reliability of $\mathrm{Al}_{2} \mathrm{O}_{3}$ dielectric. It is acknowledged that electrical double layer formed in the solution-processed metal oxide gate dielectrics will lead to higher capacitance [41,42], as shown in the inset of Fig. 6b. Because TFTs were measured in direct voltage, the capacitance per unit area of $257 \mathrm{nF} \mathrm{cm}^{-2}$ linearly extrapolated to $1 \mathrm{~Hz}$ (not the actual value) was adopted for mobility calculation to avoid the overestimation [43]. Based on these results, the relative dielectric constant $\left(\varepsilon_{\mathrm{r}}\right)$ of $\mathrm{Al}_{2} \mathrm{O}_{3}$ thin film, calculated from $\varepsilon_{\mathrm{r}}=C_{\text {ox }} d / \varepsilon_{0}$ where $d$ is the thickness, $C_{\text {ox }}$ the capacitance per unit area, $\varepsilon_{0}$ the vacuum dielectric constant, is about 8.7. This value is lower than the theoretical value of 9 due to the holes in $\mathrm{Al}_{2} \mathrm{O}_{3}$ dielectric layer. Branquinho et al. [44] also observed the similar phenomenon in the aqueous combustion synthesis of $\mathrm{Al}_{2} \mathrm{O}_{3}$ thin film.

The typical transfer characteristic curves of a-GTO$\mathrm{Al}_{2} \mathrm{O}_{3}$ TFT with the gate voltage swept from -1 to $2 \mathrm{~V}$ (Fig. 6c) exhibit excellent performance such as a maximum field-effect mobility of $69 \mathrm{~cm}^{2} \mathrm{~V}^{-1} \mathrm{~s}^{-1}$, a low SS of $76 \mathrm{mV} \mathrm{dec}^{-1}, V_{\text {th }}$ of $0.67 \mathrm{~V}, I_{\text {on }} / I_{\text {off }}$ of $1.8 \times 10^{7}$, low hysteresis voltage shift of $0.12 \mathrm{~V}$ and low operation voltage of $2 \mathrm{~V}$. The gate leakage current at $V_{\mathrm{DS}}=2 \mathrm{~V}$ of $\sim 1.1 \times 10^{-8}$ A demonstrates the reliability of these $\mathrm{Al}_{2} \mathrm{O}_{3}$ dielectrics. The histograms (Fig. S4) of the $\mu_{\mathrm{FE}}$ $\left(\sim 69 \pm 10 \mathrm{~cm}^{2} \mathrm{~V}^{-1} \mathrm{~s}^{-1}, \quad \sim 65 \pm 15 \mathrm{~cm}^{2} \mathrm{~V}^{-1} \mathrm{~s}^{-1}\right)$ and $V_{\text {th }}$ $(0.62 \pm 0.3 \mathrm{~V}, 0.71 \pm 0.3 \mathrm{~V})$ for two batches of GTO-TFT arrays demonstrate the device fabrication are reproducible. In particular, the low SS closing to the roomtemperature limit, $60 \mathrm{mV} \mathrm{dec}{ }^{-1}$, is attributed to the high quality interface [45]. The concentration of total interfacial trap states at the $\mathrm{GTO} / \mathrm{Al}_{2} \mathrm{O}_{3}$ interface calculated from $N_{\mathrm{t}}=[S S \log (\mathrm{e}) /(k T / q)-1] C_{\text {ox }} / q$ is about $4.01 \times 10^{11} \mathrm{~cm}^{-2}$ smaller than that of the aqueous IWO/ $\mathrm{Al}_{2} \mathrm{O}_{3}$ interface $\left(4.4 \times 10^{11} \mathrm{~cm}^{-2}\right)$ [46,47]. This may be attributed to the higher viscosity of 2-methoxyethanol than that of water which will form more compact sol films under the strong centrifugal force. It is worth notiing that the hysteresis property of our GTO-TFT is 

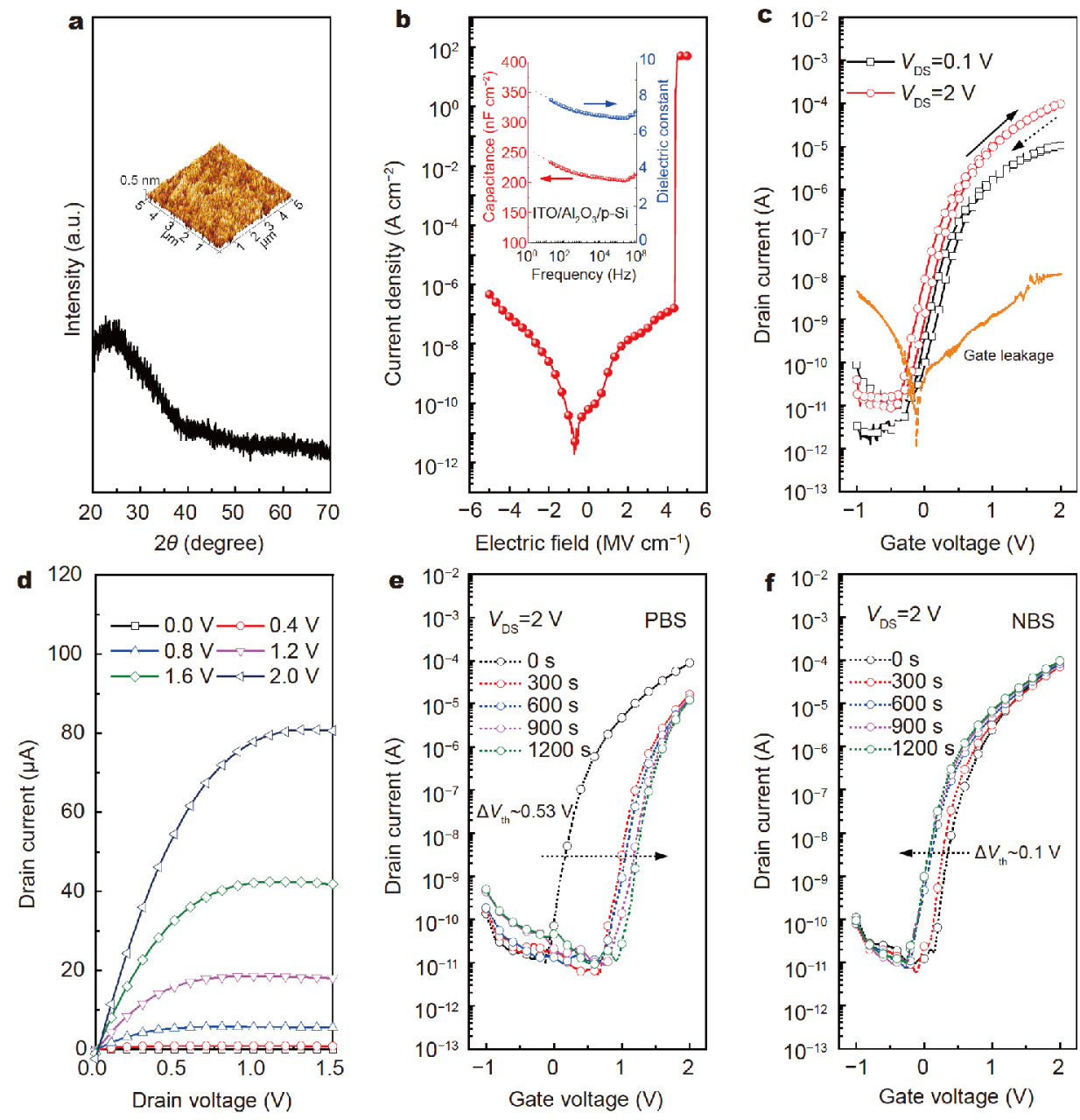

Figure 6 (a) XRD pattern of $\mathrm{Al}_{2} \mathrm{O}_{3}$ dielectric layer (inset: $\mathrm{AFM}$ surface morphology), (b) the breakdown of $\mathrm{Al}_{2} \mathrm{O}_{3}$ (inset: capacitance and dielectric constant), (c) transfer curves of $\mathrm{GTO}-\mathrm{Al}_{2} \mathrm{O}_{3}$ device, (d) output curves of $\mathrm{GTO}-\mathrm{Al}_{2} \mathrm{O}_{3}$ device, (e) PBS test, (f) NBS test.

better than that of the pure $\mathrm{SnO}_{2}$ thin film transistor derived from metalorganic precursor [15]. According to the previous report [48], a clockwise hysteresis behavior is induced by electron trapping at the acceptor-like trap states in $\mathrm{Al}_{2} \mathrm{O}_{3}$ bulk or at the $\mathrm{GTO} / \mathrm{Al}_{2} \mathrm{O}_{3}$ interface. The smaller $N_{\mathrm{t}}$ than that of $\mathrm{SiO}_{2}$ device $\left(1.04 \times 10^{12} \mathrm{~cm}^{-2}\right)$ may result in better hysteresis property. Research shows that the mobility enhancement for high- $k \mathrm{Al}_{2} \mathrm{O}_{3}$ dielectric is related to the atomic clean interface and low trap density [49]. Furthermore, the enhancement may be ascribed to the presence of trapped electrons in the solutionprocessed high- $k$ dielectrics [50]. Fig. 6d shows the corresponding output curves which exhibits excellent electron modulation capacity and hard saturation property. The device parameters are detailed in Table 1 . The PBS $(+2 \mathrm{~V})$ and NBS $(-2 \mathrm{~V})$ stabilities of GTO- $\mathrm{Al}_{2} \mathrm{O}_{3}$ devices are shown in Fig. $6 \mathrm{e}$ and $6 \mathrm{f}$. It can be seen that the
$V_{\text {th }}$ shift of GTO- $\mathrm{Al}_{2} \mathrm{O}_{3}$ device under 1,200 s stress is only $0.53 \mathrm{~V}$ and $0.1 \mathrm{~V}$ for PBS and NBS tests, respectively, which is better than $\mathrm{SiO}_{2}$ device, indicating the remarkable improvements of stabilities of the GTO device. It is reported that the origin of PBS instability of TFTs is trapped charges at the localized states at the semiconductor/sol-gel- $\mathrm{Al}_{2} \mathrm{O}_{3}$ interface [51]. Besides, we studied the stability of IZO-based and GTO channels which shows potential application (Table S1). In AOS materials, electron transport is governed by thermally activated electron hopping [33]. Fig. 7 shows energy-band diagram where localized states represent disordered metal ions. When an external electric field is applied, electrons will flow from a low energy band to a high energy band by "variable-range-hopping (VRH) percolation model" [33]. According to the VRH model, the $\mu_{\mathrm{FE}}$ of amorphous TFTs strongly depends on the gate capacitance variation 


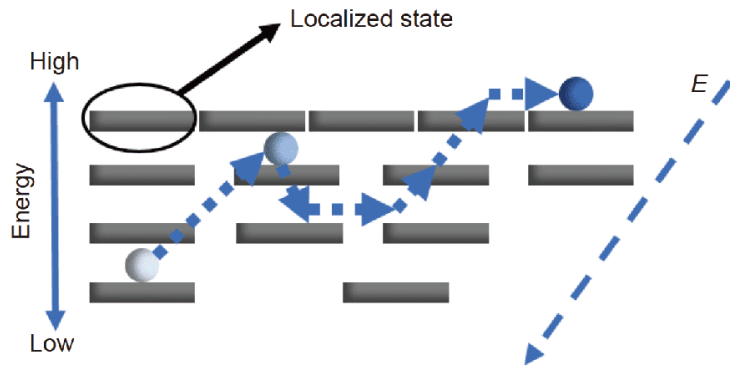

Figure 7 Energy-band diagram of the amorphous semiconductor.

which can be expressed by the reduced formula $\mu \sim \mu_{\mathrm{FE}}{ }^{0}\left(C_{\mathrm{i}} / C_{\mathrm{i}}^{0}\right)^{\gamma-2}$. Compared with the a-GTO-SiO ${ }_{2}$ device, the significant mobility enhancement is also attributed to the increase of gate capacitance $\left(12.8 \mathrm{nF} \mathrm{cm}{ }^{-2}\right.$ for $\mathrm{SiO}_{2}$, $257 \mathrm{nF} \mathrm{cm}^{-2}$ for $\mathrm{Al}_{2} \mathrm{O}_{3}$ ) [52]. The optimal performance for $\mathrm{SnO}_{2}$ based TFTs has been realized in this work. But there still exist many challenges such as the degraded mobility in the PBS test. The trapped charge at $\mathrm{GTO} / \mathrm{Al}_{2} \mathrm{O}_{3}$ interface will cause phonon scattering or coulomb scattering, leading to the mobility degradation [53]. Li et al. [54] also observed this phenomenon in IGZO/ $\mathrm{Al}_{2} \mathrm{O}_{3}$ system. In the future, more effective methods will be adopted, such as $\mathrm{SiO}_{2} / \mathrm{Al}_{2} \mathrm{O}_{3}$ bilayer, to improve the performance of the GTO device further. Related work is ongoing.

\section{CONCLUSIONS}

In this study, solution processed GTO thin films were

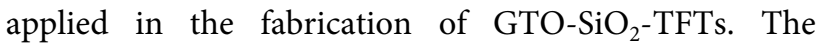
electrical properties, crystal structures, optical transparency and surface morphologies were investigated as a function of $\mathrm{Ga}$ contents. Results indicate that 20 at.\% Ga content and $350^{\circ} \mathrm{C}$ annealing temperature may be a proper range for the acceptable performance of GTOTFTs. The maximum $\mu_{\mathrm{FE}}, \mathrm{SS}, V_{\mathrm{th}}$ and $I_{\mathrm{on}} / I_{\text {off }}$ for the optimized GTO-TFT are $6.8 \mathrm{~cm}^{2} \mathrm{~V}^{-1} \mathrm{~s}^{-1}, 0.9 \mathrm{~V} \mathrm{dec}{ }^{-1}$, $0.7 \mathrm{~V}$ and $2.1 \times 10^{6}$, respectively. PBS and NBS tests of the corresponding device show positive shift of $6.6 \mathrm{~V}$ and negative shift of $6.4 \mathrm{~V}$ under $1,200 \mathrm{~s}$ bias stress which can be interpreted by charge trapping and $\mathrm{H}_{2} \mathrm{O}$ adsorption mechanisms. In order to improve the performance of GTO-TFT, $\mathrm{SiO}_{2}$ was substituted by high- $k \mathrm{Al}_{2} \mathrm{O}_{3}$ as the dielectric layer. The GTO- $\mathrm{Al}_{2} \mathrm{O}_{3}$-TFT represents the enhanced performance, such as a low operation voltage of $2 \mathrm{~V}$, a maximum $\mu_{\mathrm{FE}}$ of $69 \mathrm{~cm}^{2} \mathrm{~V}^{-1} \mathrm{~s}^{-1}$, a $\mathrm{SS}$ of $76 \mathrm{mV} \mathrm{dec}^{-1}, V_{\text {th }}$ of $0.67 \mathrm{~V}, I_{\text {on }} / I_{\text {off }}$ of $1.8 \times 10^{7}$ and a small hysteresis voltage of $0.12 \mathrm{~V}$. PBS and NBS tests demonstrate its better stabilities than $\mathrm{GTO}-\mathrm{SiO}_{2}$ device
(PBS: $0.53 \mathrm{~V}, \mathrm{NBS}:-0.1 \mathrm{~V})$. The PBS instability of devices may originate from trapped charges at the localized states at the semiconductor/sol-gel- $\mathrm{Al}_{2} \mathrm{O}_{3}$ interface. This work may pave the way for the solution-processed, low cost and low consumption In-free transparent electronic devices.

Received 28 July 2018; accepted 5 December 2018; published online 26 December 2018

1 Nomura K, Ohta H, Takagi A, et al. Room-temperature fabrication of transparent flexible thin-film transistors using amorphous oxide semiconductors. Nature, 2004, 432: 488-492

2 Liu G, Liu A, Zhu H, et al. Low-temperature, nontoxic waterinduced metal-oxide thin films and their application in thin-film transistors. Adv Funct Mater, 2015, 25: 2564-2572

3 Dong J, Han D, Li H, et al. Effect of Al doping on performance of ZnO thin film transistors. Appl Surf Sci, 2018, 433: 836-839

4 Yang J, Ren J, Lin D, et al. Amorphous nickel incorporated tin oxide thin film transistors. J Phys D-Appl Phys, 2017, 50: 355103

5 Haxel G, Hedrick JB, Orris GJ, et al. Rare earth elements: critical resources for high technology, US Geological Survey fact sheet 08702. Technical report, US Geological Survey, 2002

6 Niang KM, Cho J, Heffernan S, et al. Optimisation of amorphous zinc tin oxide thin film transistors by remote-plasma reactive sputtering. J Appl Phys, 2016, 120: 085312

7 Kyung-Chul Ok, Hyun-Jun Jeong, Hyun-Suk Kim, et al. Highly stable $\mathrm{ZnON}$ thin-film transistors with high field-effect mobility exceeding $50 \mathrm{~cm}^{2} /$ vs. IEEE Electron Device Lett, 2015, 36: 38-40

8 Kamiya T, Nomura K, Hosono H. Subgap states, doping and defect formation energies in amorphous oxide semiconductor $a$ $\mathrm{InGaZnO}_{4}$ studied by density functional theory. Phys Status Solidi A, 2010, 207: 1698-1703

9 Hosono H. Ionic amorphous oxide semiconductors: Material design, carrier transport, and device application. J Non-Crystalline Solids, 2006, 352: 851-858

10 Yang J, Meng T, Yang Z, et al. Investigation of tungsten doped tin oxide thin film transistors. J Phys D-Appl Phys, 2015, 48: 435108

11 Yang J, Fu R, Han Y, et al. The stability of tin silicon oxide thinfilm transistors with different annealing temperatures. EPL, 2016, 115: 28006

12 Yang J, Yang Z, Meng T, et al. Effects of silicon doping on the performance of tin oxide thin film transistors. Phys Status Solidi A, 2016, 213: 1010-1015

13 Ross RC, Messier R. Microstructure and properties of RF-sputtered amorphous hydrogenated silicon films. J Appl Phys, 1981, 52: 5329-5339

14 Yabuta H, Sano M, Abe K, et al. High-mobility thin-film transistor with amorphous $\mathrm{InGaZnO}_{4}$ channel fabricated by room temperature RF-magnetron sputtering. Appl Phys Lett, 2006, 89: 112123

15 Huang G, Duan L, Dong G, et al. High-mobility solutionprocessed tin oxide thin-film transistors with high- $\kappa$ alumina dielectric working in enhancement mode. ACS Appl Mater Interfaces, 2014, 6: 20786-20794

16 Jang J, Kitsomboonloha R, Swisher SL, et al. Transparent highperformance thin film transistors from solution-processed $\mathrm{SnO}_{2} /$ $\mathrm{ZrO}_{2}$ gel-like precursors. Adv Mater, 2013, 25: 1042-1047

17 Park JH, Choi WJ, Chae SS, et al. Structural and electrical properties of solution-processed gallium-doped indium oxide thin- 
film transistors. Jpn J Appl Phys, 2011, 50: 080202

18 Park WJ, Shin HS, Ahn BD, et al. Investigation on doping dependency of solution-processed Ga-doped $\mathrm{ZnO}$ thin film transistor. Appl Phys Lett, 2008, 93: 083508

19 Matsuda T, Umeda K, Kato Y, et al. Rare-metal-free highperformance Ga-Sn-O thin film transistor. Sci Rep, 2017, 7: 44326

20 Zhang X, Lee H, Kim J, et al. Solution-processed gallium-tin-based oxide semiconductors for thin-film transistors. Materials, 2018, 11: 46

21 Zhang YG, Huang GM, Duan L, et al. Full-solution-processed high mobility zinc-tin-oxide thin-film-transistors. Sci China Technol Sci, 2016, 59: 1407-1412

22 Epifani M, Arbiol J, Díaz R, et al. Synthesis of $\mathrm{SnO}_{2}$ and $\mathrm{ZnO}$ colloidal nanocrystals from the decomposition of Tin(II) 2ethylhexanoate and zinc(II) 2-ethylhexanoate. Chem Mater, 2005, 17: 6468-6472

23 Park HW, Choi MJ, Jo Y, et al. Low temperature processed InGaZnO thin film transistor using the combination of hydrogen irradiation and annealing. Appl Surf Sci, 2014, 321: 520-524

$24 \mathrm{Li} \mathrm{H}, \mathrm{Qu} \mathrm{M}$, Zhang Q. Influence of tungsten doping on the performance of indium-zinc-oxide thin-film transistors. IEEE Electron Device Lett, 2013, 34: 1268-1270

25 Rim YS, Kim DL, Jeong WH, et al. Effect of $\mathrm{Zr}$ addition on $\mathrm{ZnSnO}$ thin-film transistors using a solution process. Appl Phys Lett, 2010, 97: 233502

26 Tsaroucha M, Aksu Y, Irran E, et al. Synthesis of stannylsubstituted $\mathrm{Zn}_{4} \mathrm{O}_{4}$ cubanes as single-source precursors for amorphous tin-doped $\mathrm{ZnO}$ and $\mathrm{Zn}_{2} \mathrm{SnO}_{4}$ nanocrystals and their potential for thin film field effect transistor applications. Chem Mater, 2011, 23: 2428-2438

27 Ide K, Kikuchi Y, Nomura K, et al. Effects of excess oxygen on operation characteristics of amorphous In-Ga-Zn-O thin-film transistors. Appl Phys Lett, 2011, 99: 093507

28 Concepción P, Pérez Y, Hernández-Garrido JC, et al. The promotional effect of Sn-beta zeolites on platinum for the selective hydrogenation of $\alpha, \beta$-unsaturated aldehydes. Phys Chem Chem Phys, 2013, 15: 12048-12055

29 Lin $\mathrm{T}$, Li X, Jang J. High performance p-type $\mathrm{NiO}_{x}$ thin-film transistor by Sn doping. Appl Phys Lett, 2016, 108: 233503

30 García Núñez C, Pau JL, Ruíz E, et al. Thin film transistors based on zinc nitride as a channel layer for optoelectronic devices. Appl Phys Lett, 2012, 101: 253501

31 Fortunato E, Barquinha P, Martins R. Oxide semiconductor thinfilm transistors: A review of recent advances. Adv Mater, 2012, 24: 2945-2986

32 Banger KK, Yamashita Y, Mori K, et al. Low-temperature, highperformance solution-processed metal oxide thin-film transistors formed by a 'sol-gel on chip' process. Nat Mater, 2011, 10: 45-50

33 Lee E, Ko J, Lim KH, et al. Gate capacitance-dependent field-effect mobility in solution-processed oxide semiconductor thin-film transistors. Adv Funct Mater, 2014, 24: 4689-4697

34 Jeong S, Ha YG, Moon J, et al. Role of gallium doping in dramatically lowering amorphous-oxide processing temperatures for solution-derived indium zinc oxide thin-film transistors. Adv Mater, 2010, 22: 1346-1350

35 Yang J, Pi S, Han Y, et al. Characteristic of bismuth-doped tin oxide thin-film transistors. IEEE Trans Electron Devices, 2016, 63: 1904-1909

36 Mann JB, Meek TL, Allen LC. Configuration energies of the main group elements. J Am Chem Soc, 2000, 122: 2780-2783
37 Shin SY, Moon YK, Kim WS, et al. Characterization of the $\mathrm{SnO}_{2}$ based thin film transistors with Ga, In and Hf doping. J Nanosci Nanotechnol, 2012, 12: 5459-5463

38 Chen TC, Chang TC, Hsieh TY, et al. Investigating the degradation behavior caused by charge trapping effect under DC and AC gatebias stress for InGaZnO thin film transistor. Appl Phys Lett, 2011, 99: 022104

39 Jeong JK, Won Yang H, Jeong JH, et al. Origin of threshold voltage instability in indium-gallium-zinc oxide thin film transistors. Appl Phys Lett, 2008, 93: 123508

40 Liu PT, Chou YT, Teng LF. Environment-dependent metastability of passivation-free indium zinc oxide thin film transistor after gate bias stress. Appl Phys Lett, 2009, 95: 233504

41 Zhang $\mathrm{H}$, Guo L, Wan Q. Nanogranular $\mathrm{Al}_{2} \mathrm{O}_{3}$ proton conducting films for low-voltage oxide-based homojunction thin-film transistors. J Mater Chem C, 2013, 1: 2781-2786

42 Heo JS, Choi S, Jo JW, et al. Frequency-stable ionic-type hybrid gate dielectrics for high mobility solution-processed metal-oxide thin-film transistors. Materials, 2017, 10: 612

43 Jeong S, Lee JY, Lee SS, et al. Metal salt-derived In-Ga-Zn-O semiconductors incorporating formamide as a novel co-solvent for producing solution-processed, electrohydrodynamic-jet printed, high performance oxide transistors. J Mater Chem C, 2013, 1: 4236-4243

44 Branquinho R, Salgueiro D, Santos L, et al. Aqueous combustion synthesis of aluminum oxide thin films and application as gate dielectric in GZTO solution-based TFTs. ACS Appl Mater Interfaces, 2014, 6: 19592-19599

45 Cao Q, Xia MG, Shim M, et al. Bilayer organic-inorganic gate dielectrics for high-performance, low-voltage, single-walled carbon nanotube thin-film transistors, complementary logic gates, and $\mathrm{p}-$ n diodes on plastic substrates. Adv Funct Mater, 2006, 16: 23552362

46 Jiang Q, Lu J, Cheng J, et al. Combustion-process derived comparable performances of $\mathrm{Zn}$-(In:Sn)-O thin-film transistors with a complete miscibility. Appl Phys Lett, 2014, 105: 132105

47 Liu A, Liu G, Zhu H, et al. Eco-friendly, solution-processed In-W$\mathrm{O}$ thin films and their applications in low-voltage, highperformance transistors. J Mater Chem C, 2016, 4: 4478-4484

$48 \mathrm{Xu} \mathrm{W}$, Wang $\mathrm{H}$, Xie F, et al. Facile and environmentally friendly solution-processed aluminum oxide dielectric for low-temperature, high-performance oxide thin-film transistors. ACS Appl Mater Interfaces, 2015, 7: 5803-5810

49 Xu W, Wang H, Ye L, et al. The role of solution-processed high- $\kappa$ gate dielectrics in electrical performance of oxide thin-film transistors. J Mater Chem C, 2014, 2: 5389-5396

50 Zeumault A, Subramanian V. Mobility enhancement in solutionprocessed transparent conductive oxide TFTs due to electron donation from traps in high- $k$ gate dielectrics. Adv Funct Mater, 2016, 26: 955-963

51 Avis C, Jang J. High-performance solution processed oxide TFT with aluminum oxide gate dielectric fabricated by a sol-gel method. J Mater Chem, 2011, 21: 10649-10652

52 Tiwari N, Rajput M, John RA, et al. Indium tungsten oxide thin films for flexible high-performance transistors and neuromorphic electronics. ACS Appl Mater Interfaces, 2018, 10: 30506-30513

53 Park JS, Jeong JK, Mo YG, et al. Impact of high- $k \mathrm{TiO}_{x}$ dielectric on device performance of indium-gallium-zinc oxide transistors. Appl Phys Lett, 2009, 94: 042105

$54 \mathrm{Li} \mathrm{J}$, Zhou F, Lin $\mathrm{HP}$, et al. $\mathrm{SiO}_{x}$ interlayer to enhance the 
performance of InGaZnO-TFT with $\mathrm{AlO}_{x}$ gate insulator. Curr Appl Phys, 2012, 12: 1288-1291

Acknowledgements This work was supported by the National Natural Science Foundation of China (61471126) and a grant from Science and Technology Commission of Shanghai Municipality (16JC1400603).

Author contributions Zhang Q supervised the experimental work.
Ren J designed this work, prepared all samples and performed sample characterizations. All authors contributed to the discussion and writing of the manuscript.

Conflict of interest The authors declare no conflict of interest.

Supplementary information Supplementary data are available in the online version of the paper.
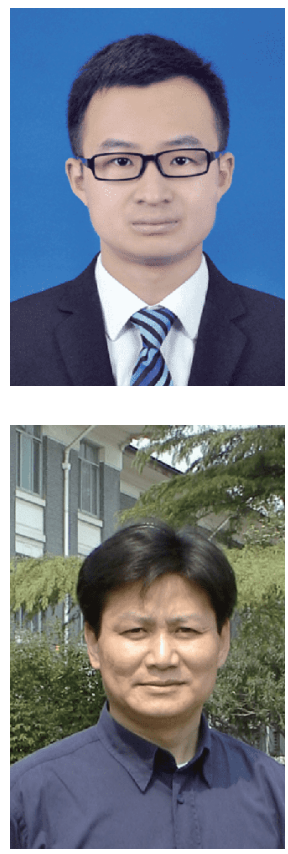

Jinhua Ren is currently pursuing the PhD degree in physics and electronics at the Department of Materials Science, Fudan University. His current research interest includes thin film transistors based on amorphous oxide semiconductors.

Qun Zhang is currently a professor at the Department of Materials Science, Fudan University. His current research interest includes oxide semiconductors, thin-film transistor, LCD, and AMOLED.

\section{溶液法制备低电压及高性能非晶GaSnO薄膜晶体管}

任锦华, 李凯文, 杨建文, 林东, 康皓清, 郡晶晶, 傅若凡, 张群 ${ }^{*}$

摘要 本文以乙二醇单甲醚为溶剂, 采用旋涂法制备了 $\mathrm{GaSnO}$ 半导体薄膜, 研究了不同 $\mathrm{Ga}$ 掺杂含量和退火温度条件下薄膜的晶体结构、 光学性质、化学价态和表面形貌信息, 同时研究了 $\mathrm{GaSnO}$ 薄膜晶体管的电学性质. 接着采用高 $k$ 值的 $\mathrm{Al}_{2} \mathrm{O}_{3}$ 薄膜作为介质层, 将上述优化好 的 $\mathrm{GaSnO}$ 薄膜作为沟道层, 制备了 $\mathrm{GaSnO} / \mathrm{Al}_{2} \mathrm{O}_{3}$ 薄膜晶体管. 实验研究发现, 器件的性能得到了显著的提升, 工作电压仅为 $2 \mathrm{~V}$, 最大场效应 迁移率为 $69 \mathrm{~cm}^{2} \mathrm{~V}^{-1} \mathrm{~s}^{-1}$, 國值电压为 $0.67 \mathrm{~V}$, 电流开关比为 $1.8 \times 10^{7}$. 溶液法制备的非晶 $\mathrm{GaSnO}$ 薄膜晶体管可能会促进高性能无铟TFT器件 以及低功耗、低成本电子器件的开发. 